\title{
Sreop
}

Revista Española de Orientación y Psicopedagogía

\section{Expósito-Casas, E. (2020). Programas y experiencias para la prevención del fracaso escolar: buenas prácticas. Editorial Sanz y Torres, 180 páginas. ISBN: 978-84-18316-06-7}

Esta obra, escrita por la doctora Expósito-Casas, es un compendio de programas y experiencias de buenas prácticas sobre la prevención del fracaso escolar.

Tiene dos partes claramente diferenciadas, incluyendo la primera las unidades 1 y 2 y la segunda las unidades 3, 4 y 5 . Dentro de cada unidad, tras la exposición de los contenidos, se incluye el resumen de la misma, la bibliografía, un glosario para clarificar los términos trabajados y unas actividades propuestas.

La primera parte, cuyo contenido es de carácter teórico, tiene como objetivo aclarar los términos que se manejan más adelante. Se define el término de buenas prácticas, tomando la definición de Ritacco Real (2011) y los atributos que marca la UNESCO en su programa Management of Social Transformations (MOST) (Santiso, 2002). Se describen las medidas que se pueden adoptar para prevenir el fracaso escolar y el abandono temprano, como son las preventivas, de intervención y de compensación. A continuación, profundiza sobre la evaluación de estos programas, que entiende como "condición sine qua non" para que lleguen a ser prácticas de éxito, presentando los distintos modelos, las condiciones que debe cumplir la evaluación de programas y termina con el diseño o planificación de la evaluación.

En la segunda parte, cuyo contenido es de carácter práctico, se exponen los programas y experiencias de centro, de aula y finaliza con otras iniciativas socioeducativas de prevención del fracaso. En este sentido, con respecto a las experiencias llevadas a cabo en los centros, destacan las iniciativas llevadas a cabo para los docentes, como el Servicio de desarrollo profesional para docentes - The Professional Development Service for Teachers (PDST)-; para implicar a las familias, como la Guía para trabajar con familias Romaníes o el Kit de herramientas para padres: Francia; y para mejorar la cultura escolar y el clima, como el programa Acción antibullying. Con respecto a las llevadas a cabo en el aula, la obra las desglosa en programas y experiencias que se han llevado a cabo a través de Aprendizaje Basado en problemas (ABp), Gamificación, Aprendizaje Servicio (ApS), Aprendizaje por Proyectos, Diseño Universal para el Aprendizaje (DUA), Aprendizaje entre iguales-tutoría entre iguales y Mobile Learning. El libro finaliza con unos ejemplos de buenas prácticas llevadas a cabo a través de otras iniciativas socioeducativas. Comienza con la labor que desempeñan o pueden llegar a desempeñar las bibliotecas, como las bibliotecas tutorizadas o su transformación a los CREA (centros de recursos de enseñanza y aprendizaje), resalta la importancia que tiene la mediación socioeducativa y su importancia en la resolución de conflictos, las experiencias formativas, en las que se destaca el papel de las actividades extraescolares, y su importancia en el alumnado más vulnerable, y por último las REOP. Vol. 31, no3, 3er Cuatrimestre, 2020, pp. 172 - 173 [ISSN electrónico: 1989-7448] 
Escuelas de Segunda Oportunidad, entendidas como los programas que permiten volver a acceder al sistema educativo al alumnado que ha sufrido el abandono prematuro del mismo.

Esta obra, de carácter teórico-práctico, ofrece un encuadre teórico para comprender qué se entiende por buenas prácticas cuando se habla de la prevención del fracaso escolar y se llena de ejemplos actuales e interesantes de buenas prácticas, lo que permite al lector un magnífico punto de partida para poder abordar esta situación de manera práctica.

\author{
Andrea Otero-Mayer \\ Investigadora predoctoral en formación \\ Facultad de Educación \\ Universidad Nacional de Educación a Distancia
}

\title{
Cómo citar esta recensión:
}

Otero-Mayer, A. (2020). Expósito-Casas, E., 2020, Programas y experiencias para la prevención del fracaso escolar: buenas prácticas, Editorial Sanz y Torres, 180 páginas. ISBN: 978-84-1831606-7 [Reseña] Revista Española de Orientación y Psicopedagogía, 31(3), 172-173. https://doi.org/10.5944/reop.vol.31.num.3.2020.29268 